\section{Viagens, expedições e itinerários desde o Mar da Irlanda: algumas considerações a partir da Confessio e da Epistola, de Patrício}

\author{
Journeys, expeditions and itineraries across the Irish Sea: some \\ notes from Patrick's 'Confessio' and 'Epistola'
}

\section{Dominique Santos*}

\begin{abstract}
Resumo: Na Antiguidade Tardia, a comunicação pelo Mar da Irlanda era um fator fundamental, pois, apesar de suas dificuldades de navegação, os caminhos marítimos eram muito mais fáceis do que os terrestres, com suas montanhas, pântanos e a necessidade de autorização para a mobilidade entre cada localidade. As trocas culturais, sociais e econômicas por via marítima eram, então, frequentes. Considerando isso, o objetivo deste artigo é apresentar algumas reflexões sobre viagens, expedições e itinerários desde o Mar da Irlanda a partir da Confessio e da Epistola, dois textos escritos por [São] Patrício no século V.
\end{abstract}

\begin{abstract}
In Late Antiquity, communication by the Irish Sea was a fundamental factor, because. Despite some difficulties in navigation, the maritime paths were much easier than the terrestrial ones, with their mountains, bogs and the need for authorization for mobility between each location. Cultural, social and economic exchanges by sea were then frequent. Considering this, the aim of this article is to present some notes on the journeys, expeditions and itineraries in the Irish Sea taking as sources the Confessio and Epistola, two texts written by [Saint] Patrick in the 5 th century.
\end{abstract}

\author{
Palavras-chave: \\ Mar da Irlanda. \\ Antiguidade Tardia. \\ São Patrício. \\ Itinerários.
}

\footnotetext{
* Professor de História Antiga da Fundação Universidade Regional de Blumenau (Furb). Coordenador do Laboratório Blumenauense de Estudos Antigos e Medievais. Professor do Programa de Pós-Graduação em História da Universidade Federal de Santa Catarina. Possui graduação (2005), mestrado (2008) e doutorado (2012) em História pela Universidade Federal de Goiás.
} 


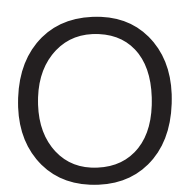
Mar da Irlanda, Muir Éireann, em irlandês, equivale à "área de mar que se estende desde a linha que une o Cabo Carnsore e o de São David, no Sul, até o Canal do Norte entre Larne e o Cabo de Corsewall" (BANNER; COLLINS; MASSIE, 1980, p. 391). É apropriado compreendê-lo, portanto, como um braço do Oceano Atlântico, com o qual ele se "comunica", como dizem os oceanógrafos, por meio do Mar Céltico. Além disso, o Atlântico é a fonte de água do Mar da Irlanda. O volume total das águas do Mar da Irlanda é de $2430 \mathrm{~km}^{2}$ e ele é relativamente raso, geralmente $<\approx 50 \mathrm{~m}$ de profundidade, exceto nas suas áreas costeiras, que pode chegar a $\approx 20 \mathrm{~m}$ (GOWEN; STEWART, 2005). Sua área de extensão se localiza entre $52-55^{\circ} \mathrm{N}$ e $3-6^{\circ} \mathrm{W}$ e conecta Irlanda, Escócia, Ilha de Man e País de Gales. Peter Brown (2013, p. 16; 51; 130; 132) certa vez se referiu ao Mar da Irlanda como o "Mediterrâneo Céltico do Norte". Apesar das diferenças entre os dois mares, a comparação pretende enfatizar que, tal qual o Mediterrâneo, o Mar da Irlanda era espaço de intercâmbios e conexões para diversos povos que habitavam a região na qual se localiza. Segundo Barry Cunliffe (2001, p. 93-4), essas locomoções podem ser compreendidas como "uma continuidade das viagens de exploração que sempre estiveram em curso desde o período Neolítico".

Nesse artigo, tratamos de um período específico, a Antiguidade Tardia, sobretudo a segunda metade do século IV e início do $V$, quando essa comunicação pelo mar era fundamental, já que era muito mais difícil se locomover por terra, enfrentando montanhas e pântanos. As viagens, expedições e itinerários utilizando os caminhos marítimos eram frequentes. Considerando isso, apresentamos, a seguir, algumas questões sobre essas movimentações desde o Mar da Irlanda, tendo como ponto de partida a Confessio e a Epistola, dois textos escritos por [São] Patrício no século V. Nossas reflexões apontam para o fato de que vários grupos étnicos efetuavam trocas em diversos níveis na região do Mar da Irlanda, que, por sua vez, não estava desconectada do restante do mundo. Por fim, considerando tais interações, o que vemos é que formas como "Britânia Romana", tão utilizadas no discurso historiográfico, tornam o olhar para essa complexidade opaco e devem ser problematizadas. Assim, esperamos que, a partir da argumentação apresentada, estejamos convencidos da necessidade de nos mantermos em alerta para tais tensionamentos, necessários para uma compreensão mais aprofundada dessa região do mundo na Antiguidade Tardia.

[São] Patrício é, junto com [Santa] Brígida e [São] Colum Cille (Columba), considerado o padroeiro da Irlanda e um sinônimo de Irishness, irlandicidade. Não por acaso, a partir de um acordo com o Governo da Irlanda, diversos países ao redor do mundo iluminam seus principais pontos turísticos na cor verde em uma homenagem dupla, ao mesmo tempo à personagem e à Ilha. O [São] Patrício que aparece nesse artigo, todavia, não é 
o padroeiro, mas o Patrício que viveu na Antiguidade Tardia, mais especificadamente no século $V$, na região do Mar da Irlanda.

É preciso ter cuidado, porém, para não cairmos na dicotomia que tem sido muito utilizada por grande parte da historiografia irlandesa mais recente para separar Patrício entre o "real Patrick", a pessoa que viveu no século $V$ e escreveu em latim alguns textos que nos chegaram, e o "ficcional Patrick", a imagem posterior feita dele principalmente nos textos hagiográficos de Muirchú e Tírechán, que escreveram no século VII. Para propósitos didáticos e a tentativa de explicar ao grande público o que os historiadores profissionais fazem, até é possível chamá-lo de "Patrício histórico" e até a página do "The Saint Patrick's Confessio Hypertext Stack Project", da Royal Irish Academy, maior referência no tema, o faz (HARVEY; CONROY; FISCHER, 2009-atual). No entanto, para um aprofundamento, essa divisão deve ser problematizada ou até mesmo evitada, pois o Patrício de Muirchú, em vários sentidos, pode estar mais próximo do Patrício "histórico", do que várias representações da historiografia moderna, bastando para isso apenas que compreendamos o sistema tropológico da narrativa de Muirchú que, de forma alguma, pode ser tomado como um mero autor de ficções (HOWLETT, 2006). O projeto desenvolvido pela Royal Irish Academy que acabamos de mencionar, por exemplo, apesar de sua excelente síntese e proposta, talvez pela necessidade de delinear claramente o que é "factual" e o que é "ficção" no que diz respeito a Patrício, acaba flertando mais com a historiografia do século XX do que com a do XXI, ou seja, ainda faz pesar sobre Muirchú e Tírechán certa culpa pela existência de um "fictional Patrick". Assim, os leitores desse artigo precisam ter em mente que as reflexões sobre as movimentações desde o Mar da Irlanda sobre as quais falamos adiante são feitas a partir da Confessio e da Epistola, mas seu autor é muito mais o [São] Patrício de Thomas O'Loughlin (2005), de David Howlett (2006) e Dominique Santos (2013) do que o de Ludiwg Bieler (1949), James Carney (1961) e Daniel Binchy (1962), ainda que esse segundo grupo de obras, mais antigas, seja fundamental.

Patrício é, na verdade, um britânico. Ele era filho de Calpurnius e neto de Potitus, um presbítero de uma vila romana na Britânia, possivelmente no fim do século IV. Ele foi para a Irlanda após ter sido raptado por piratas, algo muito frequente nessa região do Mar da Irlanda. Apesar de a Britânia ser uma prouincia romana no período em que ele viveu e estar sob proteção do Império e suas legiões, de forma alguma Roma tinha a primazia sobre o lugar. Em 367, pictos e scotos atacavam a chamada muralha de Adriano, o sul e o leste da Britânia eram atacados por saxões e francos, além do que a região possuía diversos regna independentes, governados por várias etnias e que viviam em conflito (HANSON, 1968). Ou seja, a ideia de uma "Britânia Romana" talvez não passe de uma ficção historiográfica. A vida da maioria dos bretões continuou a mesma, apenas agora preocupados com 
possíveis intervenções romanas, mas muito mais temerosos com os ataques dos scotos e os conflitos regionais. É por isso que Russel e Laycock (2010) consideram a ideia de uma "Britânia Romana" bastante imprecisa. Dessa forma, se a afirmação de que houve uma "talassocracia céltica" (BOWEN, 1970, p. 13) é perigosa, a de que o contato com a igreja britânica era muito mais importante na Antiguidade Tardia do que as relações sociais de supostos grupos célticos, indicando uma ausência de unidade nos dois lados do Mar da Irlanda, como afirma Ken Dark (2000, p. 32-33), também é. Afinal, estamos falando de um período, o século $V$, quando é possível que irlandeses já estivessem em movimentos mais direcionados para o lado galês, ou seja, para fazer assentamentos, pequenas colônias ou pirataria, há pelo menos dois séculos (CUNLIFFE, 2001). Por isso, Charles Thomas (1971) acredita que pode ter havido mais irlandeses do que germânicos na Britânia e pode ser que o século $\mathrm{V}$ tenha sido o principal período de atividade desses povos. Talvez por isso Thomas Charles-Edwards (1996, p. 27) afirme que, nesse período da Antiguidade Tardia, "o Mar da Irlanda pertencia aos irlandeses".

Quando Patrício tinha dezesseis anos de idade, ele foi raptado por piratas irlandeses pela primeira vez. Os intercâmbios e conexões entre a Hibérnia, a Britânia e o Mediterrâneo eram algo frequente. As viagens, expedições e itinerários na região possuíam relação com todos os aspectos da vida, já que os caminhos marítimos eram centrais para a vida desses povos. Para Patrício, o mais relevante deles, já que alterou o curso de sua vida, foi a pirataria. Ele nos informa sobre isso logo no início de sua Confessio (1):

\begin{abstract}
Eu, Patrício, um pecador, o mais rústico e o menor entre todos os fiéis, profundamente desprezível para muitos, tive por pai o diácono Calpurnius, filho de um certo, Potitus, falecido, um presbítero que foi morador de um vilarejo chamado Bannavem Taberniae; ele tinha uma pequena casa de campo bem próxima, onde eu fui capturado. Eu ignorava o verdadeiro Deus e junto com milhares de pessoas fui capturado e conduzido ao cativeiro na Irlanda segundo o nosso merecimento, porque nos afastamos bastante de Deus, não guardarmos os seus preceitos, nem fomos obedientes aos nossos sacerdotes, que nos exortavam a respeito da nossa salvação. E o Senhor lançou sobre nós a violência de sua cólera e nos dispersou entre vários povos até aos confins da terra, onde agora na minha pequenez, me encontro entre estrangeiros. ${ }^{1}$
\end{abstract}

Claro que as viagens na região do Mar da Irlanda já ocorriam antes, desde a PréHistória. Mas, no que diz respeito ao nosso recorte, no trecho acima, é possível observar a primeira das viagens que Patrício enfrentará. Após viver por um tempo em uma vila vinculada à administração romana na região, o filho de um diácono e de um presbítero foi capturado por piratas irlandeses. Patrício cruzou o Mar da Irlanda, então, pela primeira

\footnotetext{
${ }^{1}$ Essa e as demais citações são traduções do autor a partir do latim.
} 
vez, da Britânia em direção à Irlanda. É interessante que, ainda na continuação do verso de número um da Confessio, como podemos observar acima, ele nos informa que ele foi raptado "com milhares de pessoas". Ainda que seja um número exagerado, uma hipérbole da retórica do período, Patrício não parece ter sido raptado sozinho, mas um grupo de pessoas o acompanhou. A documentação também nos dá a possibilidade de conhecer o que ocorre subsequentemente a Patrício. Vejamos o que ele diz, em três trechos de sua Confessio $(17 ; 19 ; 21)$ :

E lá [naturalmente] uma noite no meu sono eu ouvi uma voz que me dizia: "Fazes bem em jejuar, pois brevemente partirás para a tua pátria" e novamente muito pouco tempo depois ouvi uma voz que me dizia: "Eis que teu barco está pronto" e não era em um lugar perto não, pelo contrário, estava a duzentas milhas de distância onde eu nunca estivera ou conhecera alguém. Então pouco tempo depois eu fugi e abandonei o homem com quem estivera durante seis anos e avancei na virtude de Deus, que dirigiu meu caminho para o bem e eu nada temi até que alcancei aquele barco.

E depois de três dias alcançamos a terra e caminhamos vinte e oito dias através de uma região desértica até que a comida acabou e a fome nos alcançou. No outro dia o capitão começou a me dizer: "Por que acontece isso Cristão? Tu dizes que teu Deus é grande e onipotente, porque razão tu não podes orar por nós? Pois podemos morrer de fome; é provável que jamais vejamos outro ser humano". Eu então lhes disse confiantemente: convertam-se pela fé de todo o coração ao Senhor Deus meu, pois nada é impossível para ele e hoje mesmo ele mandará alimento para vós em vosso caminho até que se saciem, pois em toda a parte ele traz abundância. E com a graça de Deus isto realmente aconteceu: eis que uma vara de porcos apareceu no caminho diante dos nossos olhos, e mataram muitos dentre os porcos. E neste lugar permaneceram por duas noites e fartaram-se daquelas carnes dos porcos e foram revigorados da fome, porque muitos deles tinha desfalecido e tinham sido abandonados semimortos à beira do caminho.

E mais uma vez, muitos anos mais tarde fui capturado pela segunda vez. Na primeira noite, eu permaneci com eles. Ouvi, então, uma voz divina que me dizia: "permanecerás durante dois meses com eles" e assim aconteceu: na sexagésima noite, o meu Senhor me libertou das mãos deles.

Podemos notar, a partir da leitura dos trechos que mencionamos, que Patrício precisou trabalhar na Irlanda, pastoreando ovelhas e porcos, onde foi escravizado por seis anos. Foi quando tentou fugir pela primeira vez. Se fez outra viagem nesse interstício não sabemos, mas, conforme podemos ler em sua narrativa, ele tentou fugir em um navio e foi parar em algum lugar que ele não menciona, provavelmente fora da Irlanda, quando foi capturado novamente. Ele escapou em um navio. Não sabemos para onde esse navio estava indo e nem se era uma viagem rotineira ou não. Será que os homens que aceitaram Patrício na embarcação sabiam que se tratava de uma pessoa escravizada em fuga? Será que já era intenção dessas pessoas vendê-lo em outro lugar, costume muito frequente na região? Era um plano, então, recebê-lo para depois repassá-lo para 
algum mercado de escravos, talvez na Gália ou na própria Britânia? São perguntas que a historiografia tem feito (SANTOS, 2013), mas que ainda não é possível responder. Para os propósitos da reflexão que aqui apresentamos, o mais interessante é perceber como Patrício se refere a essa viagem. Saíram de algum lugar na Irlanda e navegaram por três dias, conforme lemos no capítulo 19 da Confessio. O fato é que, embora não saibamos quando e nem onde, ele foi capturado novamente e levado para a Irlanda.

Parece que, para ele, as viagens por terra eram mais difíceis, de fato, do que por mar. Dentro do que ele escolhe mencionar, sempre que faz referência à terra, alguma dificuldade é apontada, os caminhos são mais árduos, o número de dias é maior. Quando ainda estava na Irlanda ele disse: "e não era em um lugar perto" e que "estava a duzentas milhas", além de ser um lugar desconhecido por ele, no qual ele "nunca estivera ou conhecera alguém", conforme vimos no capítulo 17. Depois que já estava na embarcação, Patrício não menciona grandes problemas decorridos de distância, de navegação, por conta do clima, altura das ondas ou algo assim. Ele diz apenas a duração da viagem: "e depois de três dias", como vimos no início do capítulo 19. Nesse mesmo trecho, no entanto, assim que está em terra, as coisas começam a ocorrer. Ele caminhou por vinte e oito dias, foi em uma terra deserta, a comida acabou, as pessoas o acusaram e pediram a ele uma intervenção, já que se dizia homem de deus, encontraram os porcos, e permaneceram ali por duas noites. Dessa forma, quando há alguma intervenção divina, seja por meio de sonho ou oração, as aventuras que enfrenta, e seus períodos de dificuldade, é geralmente em terra que isso ocorre, sinalizando, mais uma vez, o que a historiografia recente tem apontado, de que era mais fácil viajar pelas vias marítimas do que pelas terrestres, como vimos.

Sua segunda estadia foi menor e conseguiu fugir outra vez. Patrício, então, depois de ter cruzado o mar da Britânia para a Irlanda, após fugir de lá para algum lugar que não sabemos, foi capturado e outra vez levado para a Irlanda, de onde novamente conseguiu fugir, desta vez para a Britânia, algo que também não durará muito. Vejamos:

E depois de uns poucos anos eu estava de novo na Britânia com meus pais, que me acolheram como um filho e me rogaram que eu, após ter passado por tantas tribulações que nunca me afastasse deles; e neste lugar (naturalmente) vi numa visão noturna um homem que vinha como que da Irlanda, cujo nome era Victoricus, com inumeráveis cartas, e me deu uma delas e logo no princípio da carta estava escrito: "A voz dos irlandeses" e enquanto eu recitava o princípio da mesma, pareceu-me naquele momento ouvir as vozes daqueles que estavam perto da floresta de Voclut que fica perto do mar ocidental, e assim exclamavam como se fosse uma só voz: "Nós te rogamos, santo jovem, venhas e caminhes novamente entre nós" e eu estava tão profundamente tocado no meu coração que nem pude ler mais e assim despertei. Graças a Deus, porque depois de muitos anos, o Senhor concedeu-Ihes a sua súplica (Patrício, Confessio, 23). 
Patrício pode ser caracterizado como um bretão-romano-irlandês, além de cristão, essas são suas principais identidades. A partir do relato acima podemos ver que, definitivamente, o caminho marítimo que conduz da Britânia à Irlanda e vice-versa se tornou um itinerário frequente para ele. Raptado com dezesseis anos por piratas, é levado para a Irlanda, a primeira vez sobre a qual podemos saber que cruzou o mar nessa direção. De lá, fugiu uma primeira vez para um lugar que não sabemos, segunda viagem que podemos mapear. Porém, foi capturado e levado para a Irlanda novamente, sua terceira viagem. Dois meses depois, como vimos, fugiu novamente, agora para a Britânia, a quarta viagem. Estando ele na Britânia, diz que ouviu uma voz lhe pedindo para voltar à Irlanda e levar o cristianismo aos irlandeses. Não é o caso aqui de interpretar esse tipo de sonho, mensagem, conversas com o divino, e seus respectivos possíveis significados, questão já bastante analisada na historiografia (SANTOS, 2013). O interesse recai sobre essa que será a quinta viagem de Patrício, agora, por vontade própria e não mais por rapto e pirataria. Ele decide voltar para Irlanda, onde passará a viver e viajar diversas vezes por terra, de tuath em tuath, a divisão territorial unitária daquele período, falando com reis e tentando cristianizar os irlandeses. Não sabemos se durante esse período ele deixou a Irlanda para uma sexta viagem ou outras mais. Afinal, suas cartas são os únicos documentos escritos que temos do século $V$ irlandês e ele não nos diz mais a respeito. Porém, é possível perceber, pelo testemunho de Patrício, que o mar era mais um caminho do que uma barreira entre a Britânia e a Irlanda. Thomas Charles-Edwards (1996, p. 42) está correto quando o considera como "uma ponte entre a Irlanda e a Britânia, uma ponte percorrida principalmente por colonos e invasores irlandeses em uma direção e escravos e missionários britânicos em outra".

Em um trecho posterior de sua narrativa, Patrício afirma que "de boa vontade estaria preparado para ir para minha pátria e meus pais, e não somente lá, mas mesmo até a Gália para visitar meus irmãos" (Pat., Conf., 43). Podemos perceber, a partir daí, não somente a confirmação dessa proximidade com a Britânia, que era a terra de seus pais, mas também uma referência à possibilidade de viagem ao continente, à Gália. Faz sentido acreditar, como Thompson (1986, p. 115), que Patrício escreveu seu texto para leitores na Britânia. Acrescentaríamos apenas que, pelo menos, esse era parte do público ao qual ele se dirigia, já que também estava interessado em ser ouvido entre irlandeses. Nesse sentido, preferimos a interpretação sustentada por Thomas Charles-Edwards, que defende que o público da Confessio era da Britânia, sem esquecer, contudo, do público irlandês. Para ele, o caráter defensivo do documento, que é uma apologia em favor de Patrício, argumentando que não foi para a Irlanda enriquecer em nome da fé, nos permite 
interpretar que estava direcionado para autoridades eclesiásticas da Britânia, mas devia contemplar também algum grupo de irlandeses (CHARLES-EDWARDS, 2000, p. 218-219).

Sobre a Gália, como acompanhamos na referência da Confessio 43, que sugere que ele tinha conhecidos continentais e podia viajar para lá caso quisesse, também há menção em seu outro texto, provavelmente anterior à Confessio. Trata-se da Epistola ad Milites Corotici, que tinha como objetivo manifestar sua indignação a Coroticus, um chefe de soldados que, aparentemente, exercia a pirataria no Mar da Irlanda, ameaçando-o com a excomunhão. Patrício tinha batizado algumas pessoas e elas foram logo a seguir raptadas por Coroticus. O teor de toda a epístola é essa indignação diante do fato de que pessoas que Patrício tinha batizado estavam agora sendo vendidas aos pictos, povo que residia na região da atual Escócia, ao norte da Britânia "romana" e também a outros irlandeses. Por isso, Patrício diz que Coroticus estava "associado aos pictos" (Epistola, 1); que entregava "os cristãos nas mãos dos scotos e dos pictos" (Ep., 12); e que "homens inocentes são vendidos, cristãos são reduzidos à escravidão, principalmente aos mais indignos e abomináveis: os apóstatas pictos" (Ep., 15). Percebemos a partir dessas menções que, da mesma forma que Patrício foi raptado por irlandeses na costa da Britânia, Coroticus fazia com os cristãos na costa da Hibérnia. $O$ fato de vender seus raptados aos pictos nos indica que esse comércio se estendia ao norte. Nesse contexto, Patrício faz uma nova referência ao continente. Vejamos o que ele diz:

Este é o costume dos cristãos galo-romanos: Enviam homens santos e idôneos aos francos e outros povos com milhares de sólidos para resgatar os batizados cativos. Você prefere matar e vendê-los a povos estrangeiros que não conhecem a Deus (Pat., Ep., 14).

O trecho acima nos mostra mais um indício da relação que Patrício pode ter mantido com os cristãos da parte continental ou, pelo menos, que os conhecia, já que menciona seus costumes. Patrício os considera a partir de uma identidade mista: "galoromanos". Segundo ele, como acabamos de ler, não só os "francos", mas também "outros povos", que ele não diz quem são, aceitavam dinheiro em troca do resgate de cristãos raptados, algo que Coroticus deveria aceitar, mas não era o caso. $O$ trecho indica, então, que Patrício conhecia o contexto continental e Coroticus também pode tê-lo conhecido, ou, pelo menos, era capaz de compreender o teor do argumento de Patrício, já que o exemplo é direcionado a ele e seus soldados. Provavelmente, a situação envolvendo a pirataria também ocorria, então, em outros lugares, que se comunicavam, via marítima, com a região do Mar da Irlanda. Eram mercados de escravos e outros bens que efetivavam trocas entre si. 
O Mar da Irlanda era bem conhecido no continente desde a Antiguidade. Ele já

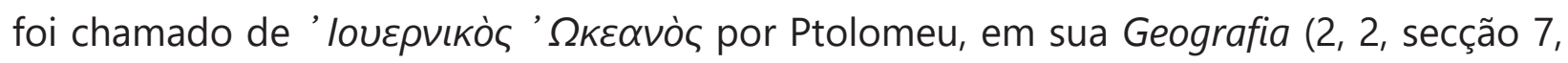
linha 2), e Marciano de Heracleia, em seu Periplus maris exteri, (Livro 2, secção 42, linhas 4-5), e já foi mencionado pelos romanos, que se referiram a ele como Oceanus Hibernicus. A Irlanda também era conhecida, apesar das diferentes nomenclaturas que recebeu ao

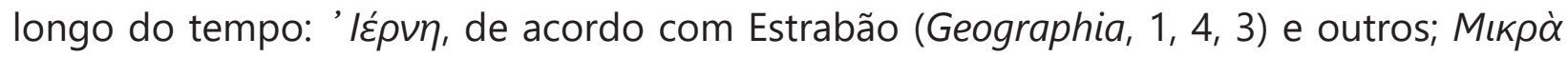

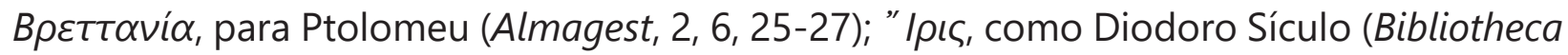
Historica, 5, 32, 3) se referiu a ela; 'louepvía, para Herodiano (De Prosodica Catholica 12, 327); Júlio César (De Bello Gallico, 5, 13), Plínio, o Velho (Naturalis Historia, 4, 102-3), Tácito (Agricola, 24) e outros a chamaram de Hibernia; de acordo com Pompônio Mela (De Chorographia 3, 53) e Juvenal (Saturae, 2, 159-63), ela era a luverna; o Pseudo- Hegésipo refere-se a ela como Scotia (Historiae, 5, 15); e para Avienus (Ora Maritima, 108-19) ela era a Insula Sacra. Várias nomenclaturas são aplicadas, indicando pequenas diferenças de percepção, porém trata-se de uma localidade conhecida para vários autores que escreveram em grego e latim.

Além das referências literárias, diversos elementos da cultura material, como anéis, broches, escudos, ânforas e várias inscrições epigráficas atestam esses contatos entre a região do Mar da Irlanda e o Mediterrâneo. Uma dessas evidências epigráficas é justamente o tipo de inscrição que ficou conhecida como Ogham. Conforme publicação neste mesmo periódico, trata-se de um hábito epigráfico irlandês originado a partir do contato com a epigrafia latina romana, sendo uma resposta ao hábito aprendido do mundo romano (SANTOS, 2016). São inscrições feitas em pedras, utilizando-se de script próprio, o Ogham, daí o nome de Ogham Stones, que pretendiam conferir ao idioma dos irlandeses da Antiguidade Tardia o mesmo status do latim. O hábito possivelmente começou com os colonizadores irlandeses da Britânia. Para Dáibhí Ó Cróinín (1995, p. 3336), os irlandeses habitantes da Britânia queriam mostrar que haviam assimilado a cultura do lugar onde viviam. Há 33 Ogham Stones na Britânia que são bilíngues e biliterais. Ou seja, elas possuem inscrições grafadas em dois scripts, o Ogham e o abc latino e, ao mesmo tempo, pelo menos dois idiomas: ou latim e irlandês ou latim e britônico.

Quando Dark (2000) chama a atenção para o relacionamento com a igreja britânica como sendo algo que tinha mais importância que os relacionamentos entre os grupos considerados célticos, então, provavelmente ele tem em mente alguém como Patrício. Dark aponta as divergências entre os clérigos britânicos e o evangelizador dos irlandeses como uma sugestão de que havia estranhamento e falta de compreensão, o que, para o autor, era indício da falta de integração entre os povos que habitavam os dois lados do Mar da Irlanda, sustentando seu argumento de que o que poderia garantir uma unidade 
na região era a igreja britânica e não a celticidade (DARK, 2000, p. 32-33). O raciocínio apresentado por Dark pode até fazer sentido, especialmente para o caso de Patrício, filho de um diácono e neto de um presbítero. Porém, somente para pensar as relações a partir da Igreja, colocando-a no centro das ações, que é o que ele parece fazer. Ele está combatendo o argumento arqueológico da "unidade cultural" do Mar da Irlanda com um argumento teológico e cultural.

É o mesmo procedimento adotado por O'Loughlin (2005) no campo das representações, quando afirma que a noção pessoal de Patrício sobre o tempo e o espaço aponta a Britânia e a Gália mais próximas do que a Britânia e a Hibérnia. Segundo o autor, Patrício achava a Hibérnia distante porque era uma terra de bárbaros, longínqua, que não cria no mesmo deus que ele, e cuja língua ele não conhecia. Além do posicionamento de Patrício mudar a partir de seu rapto, pois, após ter vivido na Irlanda, conhecido a cultura e as formas sociais irlandesas e aprendido a língua, ele se incluirá entre os locais antes vistos como bárbaros, dizendo, com possível endereçamento aos clérigos britânicos, mas direcionamento para Coroticus e seus soldados, como uma espécie de exortação, que: "para eles é indigno que sejamos irlandeses" (Pat., Ep., 16), essa é uma ideia psicológica, que considera conflitos étnicos e identitários para mesurar espaços geográficos.

A experiência que Patrício tinha com os irlandeses provavelmente era a da pirataria, pois, mesmo antes de ele ter sido um alvo desse tipo de atividade, certamente deve ter ouvido falar de casos assim. Não se tratava, então, de uma boa experiência. Esse parece ser o mesmo motivo que faz Dark perceber uma proximidade tendo a igreja britânica como centro e uma falta de compreensão quando Patrício e seus críticos não se entendem, estando ele na Hibérnia e os acusadores na Britânia. De igual modo, também é próximo do que afirma O'Loughlin. Afinal, conforme a historiografia já bem analisou, há inúmeras referências que apontam para o fato de que os clérigos britânicos e o próprio Patrício, pelo menos até ter ido para a Irlanda, viam-se como partes da civilização, enquanto que aos irlandeses apenas estava reservada a barbárie e a ignorância (SANTOS, 2013). Se o raciocínio de Dark for utilizado para pensar outros grupos sociais, sua hipótese já não se sustenta. De modo semelhante, contrariando O'Loughlin, os piratas irlandeses certamente não consideravam a Britânia tão distante assim. Também podemos afirmar que os irlandeses que viajaram através do Mar da Irlanda e fizeram seus assentamentos na Britânia e começaram a erigir inscrições em Ogham nas pedras de forma bilíngue e biliteral queriam se integrar, mas, diferentemente de Dark, para quem a igreja britânica é o que importa mais, para o caso que estamos mencionando, um fator muito mais relevante era a língua e o desejo de partilhar de um mundo administrativo romano-britânico, que podia ou não incluir a Igreja. É por isso que temos nas pedras palavras como "memória" 
e "protector" e nomes como "lustus", "Latinus" e "Emeritus", todos em latim. Todavia, não podemos nos esquecer que essas pedras mal passam de três dezenas, enquanto que, na Irlanda, há centenas delas e que não são bilíngues, muito menos biliterais. Ou seja, aqueles que não viajaram, que não cruzaram os mares, porém permaneceram na Irlanda, não começaram a escrever usando dois scripts, mas apenas o Ogham e para escrever em língua irlandesa, seu próprio idioma. Os que cruzaram o mar, mas foram para uma região em que a presença romana não era tão marcante, como no Norte, também não sentiram tal necessidade. Não queriam negociar ou se integrar com nenhuma elite romanobritânica, muito menos com qualquer igreja britânica, como Dark sugeriu. De qualquer forma, se olharmos para as condições materiais, para além dos conflitos teológicos, das representações e das identidades, sobretudo considerando as viagens, expedições e itinerários, teremos subsídios para perceber uma maior interação entre inúmeros regna e povos, o que torna essas simplificações que reduzem essas experiências a um fator, viés ou formas, como "Britânia romana", no mínimo, problemáticas.

\section{Considerações finais}

Como vimos, principalmente a partir do exame da documentação e em diálogo com O'Loughlin, Patrício, acreditava que a Britânia e a Gália eram mais próximas do que a Britânia e a Hibernia. Lendo suas cartas, porém, é possível perceber que, apesar das distâncias físicas ou mentais, reais ou imaginárias, as viagens, as expedições e os itinerários marítimos eram conhecidos na região do Mar da Irlanda. Viajar por terra implicava em enfrentar pântanos, florestas, montanhas, emboscadas e ter que pedir autorização para se locomover entre cada uma das tuatha, no caso da Irlanda, e entre cada reino, quando em outros lugares, como as regiões correspondentes aos atuais Escócia e País de Gales. Essas dificuldades, como foi possível perceber, transparecem nos escritos de Patrício, principalmente na Confessio, quando ele descreve várias situações que teve que enfrentar por terra, mas, quando faz referência às viagens marítimas, se resume a mencionar a quantidade de dias que gastou para se locomover de um lugar a outro. Cruzar o Mar da Irlanda era uma atividade frequente e somente a quantidade de vezes que Patrício nos diz que fez esse trajeto já nos permite verificar essa condição. Por meio de seus textos, vemos que os contatos e as trocas culturas, sociais e econômicas entre os territórios correspondentes às atuais regiões da Irlanda, Irlanda do Norte, Ilha de Man, Escócia, País de Gales e Inglaterra eram rotineiros.

Intercâmbios assim ocorriam desde a chamada Pré-História e continuaram em prática na Antiguidade Tardia, não somente entre as Ilhas, mas também destas com a 
região do Mediterrâneo. Quando os romanos chegaram à Britânia não estavam, então, em uma região sobre a qual não tinham qualquer conhecimento, pois, como pudemos acompanhar, há inúmeras referências à região nas fontes clássicas, além de essas trocas serem atestadas pela cultura material. Se quisermos compreender melhor a história da região, inclusive os emaranhamentos étnicos entre os povos que a habitavam, precisamos começar a prestar atenção também nas viagens marítimas.

Quando olhamos para a Britânia na Antiguidade Tardia a partir dessa ótica, vemos que a expressão "Britânia romana", tão utilizada pelos historiadores, é muito simplificador, pois desvia nosso olhar para a perspectiva romana apenas. Não se trata nem da velha disputa dicotômica entre "colonizador" e "colonizado", pois a prática de estabelecer colônias e assentamentos na Britânia, como vimos, também foi um hábito dos irlandeses, e não somente romano. Trata-se, então, de não conferir uma unidade narrativa, capaz de pensar toda essa região como se fosse um bloco cultural, como se tivesse uma unidade, sendo que, na prática, muito pelo contrário, havia dezenas e dezenas de etnias e para algumas delas a presença romana na região era pouco sentida, capaz de alterar muito pouco as práticas cotidianas, ou até mesmo irrelevante, pois esses agrupamentos estavam muito mais preocupados com as ameaças irlandesas, que também não deixavam de ser consideradas pelos próprios romanos, já que muralhas e fortes foram construídos justamente para proporcionar uma defesa contra esse tipo de ataque, principalmente a pirataria, evitando o que ocorreu com o próprio Patrício. As trocas culturais, sociais e econômicas que podemos observar a partir dessas viagens, expedições e itinerários desde - Mar da Irlanda nos possibilitam ampliar e aprofundar nossa compreensão historiográfica sobre a região, evitando a elaboração de uma história de caráter nacionalista, seja a partir da Irlanda ou da Inglaterra, e, ao mesmo tempo, também deixar de pensar a presença romana na Britânia a partir da ótica moderna, vendo-a como uma comparação antiga do fenômeno do Império Britânico, cometendo anacronismos e simplificações. Se, apesar de todo o domínio irlandês em um período que ficou conhecido como sendo a época clássica da pirataria irlandesa, em que havia diversas colônias irlandesas na região do atual País de Gales, que tem as Ogham Stones bilíngues e biliterais como testemunha dessa presença, quando os irlandeses também chegaram ao norte da Britânia, não devemos nos referir a ele como sendo o momento de uma "talassocracia céltica", também não devemos aplicar o mesmo raciocínio para explicar a presença romana. A forma "Britânia romana" é um "romano centrismo" cometido por quem estuda a história romana do ponto de vista da História ou dos Estudos Clássicos. Trata-se do reducionismo inverso à talassocracia céltica, que por vezes recebeu acusação de ser uma perspectiva "celto-cêntrica". Apesar do imperialismo britânico, do gosto inglês por monarquias, do colonialismo britânico 
moderno e contemporâneo, seja nas ilhas, próximas ou distantes, ou em outras regiões, das aproximações que a historiografia inglesa costuma fazer tendo o Império Romano como referência, e de embates políticos atuais, como o Brexit, é importante considerar que a Britânia, a Hibérnia e Ilhas do Atlântico Norte, na Antiguidade Tardia, eram multiétnicas e pluriculturais.

\section{Referências}

\section{Documentação textual}

MUIRCHÚ MOCCU MACHTÉNI. 'Vita Sancti Patricii'. Life of Saint Patrick. Translated by David Howlett. Dublin: Four Courts Press, 2006.

PATRICK. Confession et Lettre a Coroticus. Traduit par R. P. C. Hanson. Paris: Du Cerf, 1968. PATRICK. Confessio. In: . Libri Epistolarum Santi Patricii Episcopi. Edited and translated by Ludwig Bieler. Dublin: Royal Irish Academy, 1993.

PATRICK. Confessio. In: The Book of Letters of Saint Patrick the Bishop. Edited and translated by David Howlett. Dublin: Four Courts Press, 1994.

PATRÍCIO. Confessio e Epistola. In: SANTOS, D. (trad.). São Patrício por ele mesmo: Confissão e Carta aos soldados de Coroticus. The Saint Patrick's Confessio Hypertext Stack Project. Dublin: Royal Irish Academy. Disponível em: <www.confessio.ie>. Acesso em: 26 fev. 2021.

\section{Obras de apoio}

BANNER, F. T.; COLLINS, M. B.; MASSIE, K. S. (ed.). The North-West European shelf seas: the sea bed and the sea in motion II. Amsterdam: Elsevier, 1980, p. 391-413. 24 v.

BIELER, L. The life and legend of Saint Patrick. Dublin: Clonmore \& Reynolds, 1949.

BIELER, L. The Patrician texts in the Book of Armagh. Dublin: Dublin Institute for Advanced Studies, 2004.

BINCHY, D. Patrick and his biographers: ancient and modern. Studia Hibernica, n. 2, p. 7-173, 1962.

BOWEN, E. G. Britain and the British seas. In: MOORE, D. (ed.). The Irish Sea Province in Archaeology and History. Cardiff: Cambrian Archaeological Association, 1970, p. 13-28.

BROWN, P. The rise of Western Christendom: triumph and diversity, A.D. 200-1000. Oxford: Wiley-Blackwell, 2013. 
CARNEY, J. The problem of Saint Patrick. Dublin: DIAS, 1961.

CHARLES-EDWARDS, T. M. Early Christian Ireland. Cambridge: Cambridge University Press, 2000.

CHARLES-EDWARDS, T. M. Irish Warfare before 1100. In: BARLETT, T.; JEFERRY, K. (ed..). A military history of Ireland. Cambridge: Cambridge University Press, 1996, p. 26-51.

CUNLIFFE, B. Facing the ocean: The Atlantic and its peoples 8000 BC-AD 1500. Oxford: Oxford University Press, 2001.

DARK, K. Britain and the end of Roman Empire. Charleston: Tempus, 2000.

GOWEN, R. J.; STEWART, B. M. The Irish Sea: nutrient status and phytoplankton. Journal of Sea Research, n. 54, p. 36-50, 2005.

HANSON, R. P. C. Saint Patrick: his origins and career. London: Clarendon Press, 1968.

HARVEY, A.; CONROY, J.; FISCHER, F. Saint Patrick's Confessio Hypertext Stack Project. Dublin: Royal Irish Academy, 2009-present. Disponível em < https://www.confessio. ie>. Acesso em: 26 fev. 2021.

HOWLETT, D. Vita Sancti Patricii. Life of Saint Patrick. Dublin: Four Courts Press, 2006.

Ó CRÓINÍN, D. Early Medieval Ireland 400-1200. London: Longman, 1995.

O'LOUGHLIN, T. Discovering Saint Patrick. London: Darton, Longman \& Todd, 2005.

PAOR, L. Saint Parick's world. Indiana: University of Notre Dame Press, 1993.

RUSSELL, M.; LAYCOCK, S. Unroman Britain: exposing the great myth of Britannia. Stroud: The History Press, 2010.

SANTOS, D. How the historical Patrick was transformed into the St. Patrick of religious faith? New York: The Edwin Mellen Press, 2013.

SANTOS, D. As Ogham Stones: fontes para o estudo da Hibernia e da Britannia romana (e pós-romana). Romanitas, v. 8, p. 35-50, 2016.

THOMAS, C. Britain and Ireland in Early Christian times. London, 1971.

THOMPSON, E. A. Who was Saint Patrick? New York: St. Martin's Press, 1986. 